\title{
- ПРОБЛЕМНІ КОНТЕКСТИ СУЧАСНОЇ ГУМАНІТАРИСТИКИ: КОНЦЕПТУАЛЬНІ ОСНОВИ ЗМІСТУ НАВЧАЛЬНОЇ ДИСЦИПЛІНИ «ІНФОРМАЦІЙНИЙ МЕНЕДЖМЕНТ»
}

\section{- Касьян Владислав Володимирович}

Кандидат фрілософьських наук,

ORCID: 0000-0003-0539-4531, e-mail: kasjanvv@gmail.com, Київський національний університет культури і мистецтв, вул. Є. Коновальця, 36, Київ, Україна, 01133

\section{- Для цитування:}

Касьян, В.В. (2021). Проблемні контексти сучасної гуманітаристики: концептуальні основи змісту навчальної дисципліни «інформаційний менеджмент». Питання культурології, (37), 159168. doi: https://doi.org/10.31866/2410-1311.37.2021.236017.

\section{- Анотація}

Мета статті - виявлення концептуальних основ формування змісту дисципліни «Інформаційний менеджмент» для підготовки фрахівців за спеціальністю 029 «Інформаційна, бібліотечна та архівна справа». Методологія дослідження базується на сукупності загальнонаукових методів узагальнення, систематизації і прогнозування. Гіпотетичний аналіз дав змогу розробити зміст дисципліни «Інформаційний менеджмент» для спеціальності 029 «Інформаційна, бібліотечна та архівна справа» відповідно до предметної галузі діяльності майбутнього фрахівця та стандарту вищої освіти за спеціальністю. Наукова новизна дослідження полягає у тому, що обґрунтовано концептуальний підхід до змісту навчальної дисципліни «Інформаційний менеджмент», релевантний профрілю підготовки фрахівців за спеціальністю 029 «Інформаційна, бібліотечна та архівна справа», який базується на підходах представників науково-педагогічної школи бібліотечно-інформаційної освіти до розуміння сутності інформаційного менеджменту та враховує сучасні тенденції розвитку наук інформаційно-управлінського спрямування. Висновки. Доведено, що для відповідності змісту предметної області (інформаційні та документні системи установ, технології управління інформаційними, архівними та бібліотечними справами), і розуміння інформаційного менеджменту як управління інформацією та управління за допомогою інформації з урахуванням комунікативної складової діяльності, у навчальному курсі «Інформаційний менеджмент» для студентів спеціальності «Інформаційна, бібліотечна та архівна справа» необхідно виробити цілісну концепцію у системних дослідженнях і забезпечити дидактичну трансляцію наукових результатів у навчальний процес. Тож розробка цілісної теорії інформаційного менеджменту, основні положення якої могли б стати основою 
змісту даної навчальної дисципліни, є необхідною для всебічної підготовки фахівців зазначеної галузі.

Ключові слова: інформаційний менеджмент; підготовка фахівців; спеціальність 029 «Інформаційна, бібліотечна та архівна справа»

\section{Вступ}

«ннормаційна, бібліотечна та архівна справа» - єдина в Україні спеціальність інформаційно-комунікативного та соціально-комунікативного профілю. Освітні програми, що розробляються у її межах, характеризуються інноваційністю пропонованих спеціалізацій, одночасно зберігаючи сталість ознак професій та наступність у базових дисциплінах, зміст яких оновлюється відповідно до сучасних концепцій.

Однією з таких дисциплін є «Інформаційний менеджмент», який викладається у навчальних закладах і наповнюється змістом відповідно до освітніх програм та спеціальностей, для яких створюються робочі програми (нині силабуси). Тож розробка цілісної теорії інформаційного менеджменту, основні положення якої могли б стати основою змісту навчальної дисципліни є необхідною для всебічної підготовки фрахівців даної галузі.

Інформаційний менеджмент як напрям наукових досліджень знаходиться упродовж багатьох років у полі уваги науковців та професорсько-викладацького складу закладів вищої освіти. Перші посібники з інформаційного менеджменту були видані у 2004 р. (Матвієнко, 2004b) та 2007 р. (Матвієнко \& Цивін, 2007) у межах науково-педагогічної школи бібліотечно-інформаційної освіти Київського національного університету культури і мистецтв, які увійшли до списку обов'язкової літератури, що пропонується при вивченні інформаційного менеджменту у закладах вищої освіти України. В освітньому полі наявні також навчальні посібники з інформаційного менеджменту (Кобилін \& Самородов, 2017; Спрінсян \& Бірюкова, 2012), у яких даються авторські концепції і підходи до викладання інформаційного менеджменту.

Загалом серед робочих програм (силабусів) останніх років, які презентують зміст дисципліни «Інформаційний менеджмент», виділимо такі підходи: технікотехнологічний - управління впровадженням і використанням інформаційних технологій та інформаційно-орієнтований - управління за допомогою інформації.

У контексті освітнього потенціалу інформаційного менеджменту статті, представлені на сайті Національної бібліотеки України імені В. І. Вернадського, презентують дослідження 1999-2019рр. (Гончарова, 1999; Матвієнко, 2004 а; Матвієнко \& Цивін, 2017) і віддзеркалюють розуміння інформаційного менеджменту, яке фрормувалось у науковому дискурсі упродовж цих років. Водночас відзначимо недостатність системних досліджень у галузі інформаційного менеджменту.

\section{- Мета статті}

Мета статті - виявити концептуальні основи фрормування змісту дисципліни «Інформаційний менеджмент» для підготовки фахівців за спеціальністю 029 «Інформаційна, бібліотечна та архівна справа» (ІБАС). Методологія дослі- 
дження базується на сукупності загальнонаукових методів узагальнення, систематизації і прогнозування. Гіпотетичний аналіз надав можливість розробити зміст дисципліни «Інформаційний менеджмент» для спеціальності 029 «Інформаційна, бібліотечна та архівна справа» відповідно до предметної галузі діяльності майбутнього фахівця та стандарту вищої освіти за спеціальністю. Наукова новизна - обґрунтовано концептуальний підхід до змісту навчальної дисципліни «Інформаційний менеджмент», релевантний профрілю підготовки фрахівців за спеціальністю 029 «Інформаційна, бібліотечна та архівна справа».

\section{- Виклад матеріалу дослідження}

Виходячи з розуміння сутності спеціальності ІБАС та визначеного у стандарті вищої освіти теоретичного змісту предметної області (Міністерство освіти і науки України, 2018) - інформаційні та документні системи установ, технології управління інформаційними, архівними та бібліотечними справами передбачає розуміння інформаційного менеджменту як управління інфрормацією та управління за допомогою інформації (Гиляревский, 2009, с. 17). Розвиток цифрового середовища діяльності підприємств і організацій, а також сучасні концепції менеджменту, пов'язані з документно-інформаційною діяльністю, зокрема менеджмент управління знаннями та менеджмент контенту, спонукають розглянути їх у концепції інфрормаційного менеджменту.

Тому, при формуванні концепції навчальної дисципліни Інформаційний менеджмент, було запропоновано зміст, структуру та завдання. Змістом дисципліни є: новий тип управління організацією на основі комплексного використання усіх видів інформації (науково-дослідної, технологічної, матеріально-технічної, кадрової, фрінансової та ін.); розробка і реалізація внутрішньої та зовнішньої комунікативної політики організації, причому мета діяльності цієї галузі відокремлюється від IT-менеджменту - управління впровадженням і використанням інформаційних технологій. Структурою: оперативне використання інформації як стратегічного ресурсу з метою забезпечення конкурентоздатності організації; управління процесами опрацювання інфрормації; використання інфрормації для цілеспрямованого формування зовнішньої і внутрішньої комунікативної політики організації. Завданнями: пошук, формування, аналіз інформаційних ресурсів із метою використання їх у діяльності організації; пошук нових, більш ефективних способів організації інфрормаційної діяльності, активізації і розвитку наявних інформаційно-технологічних ресурсів, а також форм їх раціонального використання (Матвієнко, 2004b, с. 11; Матвієнко \& Цивін, 2007, с. 9).

Такий підхід іманентно містить комунікативну складову в інфрормаційному менеджменті і не суперечить розвитку цифррових технологій і цифррових ресурсів у забезпеченні діяльності організацій.

Інформаційний менеджмент, бувши спрямованим на управління інформацією та управління за допомогою інформації, актуалізує питання управління персоналом, функціонально задіяним у опрацюванні інформації, створенні інформаційних продуктів та послуг. Відтак у цій сфері діяльності постають соціально-психологічні аспекти взаємодії професійних ресурсів інформаційної діяльності, специфріка яких має бути окреслена у змісті навчальної дисципліни. 
Важливим елементом інформаційного менеджменту є політика інформаційної безпеки організації. I хоча у контексті інфрормаційного менеджменту для фахівців спеціальності 029 «Інформаційна, бібліотечна та архівна справа» не йдеться про питання кібербезпеки, технічного захисту інформації тощо. Однак політика інформаційної безпеки - це набір вимог, правил, обмежень та рекомендацій, які регламентують порядок інформаційної діяльності в організації і спрямовані на досягнення і підтримку стану інформаційної безпеки організації та є невід'ємною частиною діяльності організацій, зокрема й тих, які входять до предметної галузі діяльності бібліотек і архівів.

Таким чином, навчальна дисципліна «Інформаційний менеджмент» може містити такі розділи:

- теоретико-методологічні основи виникнення й розвитку інформаційного менеджменту;

- інформаційні ресурси та інформаційні потоки в організації;

- інформаційні продукти та послуги;

- управління процесами опрацювання інформації в організації;

- комунікативні стратегії організації;

- соціально-психологічні особливості інформаційного менеджменту; зації;

- управління професійними ресурсами інформаційної діяльності в органі-

- політика інформаційної безпеки організації.

У формуванні змісту дисципліни «Інформаційний менеджмент» для спеціальності 029 «Інформаційна, бібліотечна та архівна справа» звернімо увагу на об'єднані у спеціальності бібліотечну, архівну справу, інформаційну діяльність у широкому її розумінні та документознавчі освітні програми, не артикульовані у назві освітньої спеціальності. У цьому контексті постає питання: чи має зміст дисципліни «Інформаційний менеджмент» бути інтегрованим для всіх освітніх програм у межах спеціальності або ж має враховувати специфріку кожної освітньої програми окремо? Вважаємо, що можливі обидва варіанти змістового наповнення дисципліни - як узагальнений для всіх студентів спеціальності, так і диференційований відповідно до освітніх програм із попереднім аналізом педагогічної доцільності кожного з варіантів.

Важливою $€$ також «цифрова» складова у галузі «Інформаційна, бібліотечна та архівна справа». У цьому контексті звернемо увагу на вебконтент організації (бібліотеки, архіву, органів влади та управління тощо), який сьогодні $€$ суттєвою складовою цілеспрямованого формування зовнішньої і внутрішньої комунікативної політики організації. У діяльності фахівця спеціальності «Інформаційна, бібліотечна та архівна справа» постають нові професійні завдання з освоєння віртуального інформаційного середовища, зокрема добір контенту для представлення у веб, планування життєвого циклу вебконтенту, його супровід - комплекс робіт, спрямованих на постійне оновлення контенту сайту з метою його відповідності інтересам і запитам користувачів, та низка інших завдань, які потребують управління, планування, організації та контролю цієї діяльності. Варто також врахувати такі завдання, як ведення новинних стрічок і представництв у соціальних мережах, модерування обговорень на сайті, фору- 
мі і у соціальних мережах - діяльність, яка входить до сфрери створення інформаційних ресурсів і потребує застосування функцій менеджменту. Ці завдання представлені у стандарті вищої освіти за спеціальністю (Міністерство освіти і науки України, 2018). Тож менеджмент вебконтенту як спеціальний вид інформаційно-комунікативної та інформаційно-управлінської діяльності $€$ складовою інформаційного менеджменту.

Наголосимо, що до структури інформаційного менеджменту закордонні дослідники долучають управління знаннями (knowledge management) - напрям, який вітчизняні науковці у галузі теорії й методики професійної освіти розглядають як методологічний орієнтир пошуку концепту спеціальності 029 «Інформаційна, бібліотечна та архівна справа» (Матвієнко \& Цивін, 2018а).

У дослідженнях розвитку знаннєорієнтованих концепцій менеджменту, які структурно і функціонально уточнюють зміст, О. Матвієнко та М. Цивін звертають увагу на функціонування у предметному полі управління знаннями нових ключових термінів. Йдеться про «управління ідеями» (англ. idea management) технологія, яка дає змогу генерувати, збирати, розподіляти і використовувати ідеї, запропоновані співробітниками компанії, її клієнтами, партнерами або звичайними користувачами. Крауд-технології (англ. crowd - «натовп»), які становлять собою набір ефективних інструментів, що працюють за принципом зробленого багатьма людьми внеску у спільну справу. Таку діяльність описує термін «краудсорсине» (англ. crowdsourcing, crowd - «натовп» і sourcing - «використання ресурсів») - залучення до розв'язання проблем інноваційної діяльності широкого кола осіб для використання їхніх творчих здібностей, знань та досвіду на добровільних засадах із використанням інформаційно-комунікаційних технологій. На сьогодні використання цих технологій стало практикою - від бібліотек до органів державної влади - і потребує керованого застосування у частині надання і опрацювання використовуваних інформаційних ресурсів (Матвієнко \& Цивін, 2018b).

У сорері уваги знаходяться також питання розвитку цифрової гуманітаристики у сучасному бібліотекознавстві та у підготовці кадрів, зокрема й за кордоном (Воскобойнікова-Гузєва, 2019; Гончарова, 1999; Ярошенко \& Чуканова, 2018). Однак цей напрям досліджень знаходиться на стадії розвитку та становлення і не виокремився як навчальний курс у освітньому просторі. Тому доцільним вважаємо додати відповідний розділ до змісту курсу «Інформаційний менеджмент», оскільки він окреслює перспективи розвитку інформаційного менеджменту у контексті цифровізації інформаційних ресурсів.

При формуванні змісту навчальної дисципліни «Інформаційний менеджмент» не можна оминути увагою техніко-технологічні засоби підтримки діяльності у цій галузі і зокрема визначення рівня «заглиблення» майбутніх фрахівців у деталі їх розробки та впровадження. Обізнаність фрахівців з інформаційної діяльності із сучасними цифровими технологіями має бути необхідною і достатньою для виконання завдань, пов'язаних із використанням цифрових технологій у предметній діяльності та базуватись на цифровій культурі фахівця, його цифрових компетенціях і насамперед на здатності до подальшої освіти і самоосвіти. 


\section{- Висновки}

Отже, навчальний курс «Інформаційний менеджмент» для студентів спеціальності «Інформаційна, бібліотечна та архівна справа» має відповідати змісту предметної області - інформаційні та документні системи установ, технології управління інформаційними, архівними та бібліотечними справами. Важливим $€$ також розуміння інформаційного менеджменту як управління інформацією та управління за допомогою інформації з урахуванням комунікативної складової діяльності у предметній галузі. 3 цією метою у навчальному курсі мають бути представлені сучасні концепції менеджменту, які стосуються документноінформаційної діяльності, зокрема менеджмент вебконтенту, управління знаннями, цифрова гуманітаристика та інші напрями інформаційно-управлінської діяльності.

Міждисциплінарна галузь «Інформаційний менеджмент» потребує вироблення цілісної концепції у системних дослідженнях і дидактичної трансляції наукових результатів у навчальний процес підготовки фахівців за спеціальністю «Інформаційна, бібліотечна та архівна справа».

\section{- Список використаних джерел}

Воскобойнікова-Гузєва, О. (2019). Цифрова гуманітаристика в системі вищої освіти Канади. Неперервна профресійна освіта: теорія і практика, 2, 58-62.

Гиляревский, Р. С. (2009). Информационный менеджмент: управление информацией, знанием, технологией. Профессия.

Гончарова, Н. (1999). Інформаційний менеджмент та підготовка фрахівців-архівознавців. Студії з архівної справи та документознавства, 4, 62-64.

Дубровіна, Л. А., Лобузіна, К. В., Онищенко, О.С., \& Боряк, Г.В. (2020). Цифрова гуманітаристика та бази даних документальної культурної спадщини в бібліотеках України. Рукописна та книжкова спадщина України, 25, 290-309.

Кобилін, А. М., \& Самородов, Б. В. (2017). Інформаційний менеджмент. Новий Світ2000.

Матвієнко, О. В. (2004а). Інформаційний менеджмент: аналіз предметного поля. Вісник Книжкової палати, 8, 13-17.

Матвієнко, О.В.(2004b). Основи інфрормаційного менеджменту. Центр навчальної літератури.

Матвієнко, О. В., \& Цивін, М.Н.(2007). Інфрормаційний менеджмент. Видавничий Дім "Слово".

Матвієнко, О.В., \& Ц Цивін, М.Н. (2017). Інформаційний менеджмент як основа концептуалізації моделі фрахівця з інфрормаційної справи. Вісник Книжкової палати, 4, 27-30.

Матвієнко, О. В., \& Цивін, М.Н.(2018а). Знанієорієнтовані концепції у дискурсі сучасної теорії та практики менеджменту. В Економіка і культура України в світових глобалізаційних процесах: позиціонування і реалії, Матеріали III Міжнародної науково-практичної конференції, Україна, Київ, 21-22 березня 2018 р. (с. 123126). Видавничий центр КНУКіМ.

Матвієнко, О. В., \& Цивін, М.Н.(2018b). "Управління знаннями" як методологічний орієнтир пошуку концепту спеціальності 'Інформаційна, бібліотечна та архівна 
справа". Український журнал з бібліотекознавства та інфоормаційних наук, 2, 66-76.

Матвієнко, О. В., \& Цивін, М.Н.(2020). "ІТ-бібліотекарі": пошук шляхів інноваційності, трудової мобільності чи зміна ціннісних орієнтирів професії? Вісник Книжкової палати, 3, 25-30.

Міністерство освіти і науки України. (2018). Стандарт вищої освіти України: перший (бакалаврський) рівень, галузь знань 02 Культура і мистецтво, спеціальність 029 "Інформаційна, бібліотечна та архівна справа": затверджено і введено в дію Наказом Міністерства освіти і науки України від 12.12.2018 р. № 1378. https://cutt.ly/3zSKrGH

Спрінсян, В. Г., \& Бірюкова, Т. Л. (2012). Ресурси та технології інфформаційного менеджменту. Одеський національний політехнічний університет.

Ярошенко, Т., \& Чуканова, С. (2018). Роль цифрової гуманітаристики у модернізації сучасного бібліотекознавства. Український журнал з бібліотекознавства та інфоормаційних наук, 1, 10-17.

\section{- References}

Dubrovina, L. A., Lobuzina, K. V., Onyshchenko, O. S., \& Boriak, H. V. (2020). Tsyfrova humanitarystyka ta bazy danykh dokumentalnoi kulturnoi spadshchyny $v$ bibliotekakh Ukrainy [Digital humanities and databases of documentary cultural heritage in libraries of Ukraine]. Manuscript and Book Heritage of Ukraine, 25, 290-309 [in Ukrainian].

Gilyarevskiy, R. S. (2009). Informatsionnyy menedzhment: upravlenie informatsiey, znaniem, tekhnologiey [Information management: information, knowledge, technology management]. Professiya [in Russian].

Honcharova, N. (1999). Informatsiinyi menedzhment ta pidhotovka fakhivtsiv-arkhivoznavtsiv [Information management and training of archival specialists]. Studii z Arkhivnoi Spravy ta Dokumentoznavstva, 4, 62-64 [in Ukrainian].

Kobylin, A. M., \& Samorodov, B. V. (2017). Informatsiinyi menedzhment [Information Management]. Novyi Svit-2000 [in Ukrainian].

Matviienko, O. (2004a). Informatsiinyi menedzhment: analiz predmetnoho polia [Information management: subject field analysis]. Bulletin of the Book Chamber, 8, 13-17 [in Ukrainian].

Matviienko, O. V. (2004b). Osnovy informatsiinoho menedzhmentu [Fundamentals of Information Management]. Tsentr navchalnoi literatury [in Ukrainian].

Matviienko, O. V., \& Tsyvin, M. N. (2007). Informatsiinyi menedzhment [Information Management]. Vydavnychyy Dim "Slovo" [in Ukrainian].

Matviienko, O. V., \& Tsyvin, M. N. (2017). Informatsiinyi menedzhment yak osnova kontseptualizatsii modeli fakhivtsia $\mathrm{z}$ informatsiinoi spravy [Information management as a basis for conceptualization of the model of an information specialist]. Bulletin of the Book Chamber, 4, 27-30 [in Ukrainian].

Matviienko, O. V., \& Tsyvin, M. N. (2018a). Znaniieoriientovani kontseptsii u dyskursi suchasnoi teorii ta praktyky menedzhmentu [Knowledge-oriented concepts in the discourse of modern management theory and practice]. In Ekonomika i kultura Ukrainy v svitovykh hlobalizatsiinykh protsesakh: pozytsionuvannia i realii [Economy and Culture of Ukraine in World Globalization Processes: Positioning and Realities], 
Proceedings of the III International Scientific Conference, Ukraine, Kyiv, March 2122, 2018 (pp. 123-126). KNUKiM Publishing Center [in Ukrainian].

Matviienko, O. V., \& Tsyvin, M. N. (2018b). "Upravlinnia znanniamy" yak metodolohichnyi oriientyr poshuku kontseptu spetsialnosti "Informatsiina, bibliotechna ta arkhivna sprava" ["Knowledge Management" as a methodological guideline for finding the concept of the specialty "Information, Library and Archival Affairs"]. Ukrainian Journal of Library and Information Sciences, 2, 66-76 [in Ukrainian].

Matviienko, O. V., \& Tsyvin, M. N. (2020). "IT-bibliotekari": poshuk shlyakhiv innovatsiynosti, trudovoi mobilnosti chy zmina tsinnisnykh oriientyriv profesii? ["IT-librarians": finding ways of innovation, job mobility or changing the values of the profession?]. Bulletin of the Book Chamber, 3, 25-30 [in Ukrainian].

Ministry of Education and Science of Ukraine. (2018b). Standart vyshchoi osvity Ukrainy: pershyi (bakalavrskyi) riven, haluz znan 02 Kultura i mystetstvo, spetsialnist 029 "Informatsiina, bibliotechna ta arkhivna sprava" [Standard of higher education of Ukraine: first (bachelor's) level, field of knowledge 02 Culture and art, specialty 029 "Information, Library and Archival Affairs"]: Approved and put into effect by the Order of the Ministry of Education and Science of Ukraine dated 12.12.2018 N 1378. https://cutt.ly/3zSKrGH [in Ukrainian].

Sprinsian, V. H., \& Biriukova, T. L. (2012). Resursy ta tekhnolohii informatsiinoho menedzhmentu [Resources and Technologies of Information Management]. Odessa National Polytechnic University [in Ukrainian].

Voskoboinikova-Huzieva, O. (2019). Tsyfrova humanitarystyka v systemi vyshchoi osvity Kanady [Digital humanities in the system of higher education in Canada]. Neperervna Profesiina Osvita: Teoriia i Praktyka, 2, 58-62 [in Ukrainian].

Yaroshenko, T., \& Chukanova, S. (2018). Rol tsyfrovoi humanitarystyky u modernizatsii suchasnoho bibliotekoznavstva [The role of digital humanities in the modernization of modern library science]. Ukrainian Journal of Library and Information Sciences, 1 , 10-17 [in Ukrainian].

\section{- PROBLEMATIC CONTEXTS OF MODERN HUMANITIES: CONCEPTUAL FRAMEWORK OF THE CONTENT OF THE ACADEMIC DISCIPLINE "INFORMATION MANAGEMENT"}

\section{Vladyslav Kasian}

PhD in Philosophy, ORCID: 0000-0003-0539-4531, e-mail: kasjanvv@gmail.com, Kyiv National University of Culture and Arts, Kyiv, Ukraine

\section{- Abstract}

The purpose of the article is to identify the conceptual basis for the formation of the content of the discipline "Information Management" for the training of specialists in the 
specialty 029 "Information, library and archives". The research methodology is based on a set of general scientific methods of generalization, systematization, and forecasting. The hypothetical analysis made it possible to develop the content of the discipline "Information Management" for the specialty 029 "Information, library and archives" in accordance with the subject area of the future specialist's activity and the standard of higher education. The scientific novelty of the study is that the conceptual approach to the content of the discipline "Information Management" is substantiated, which is relevant to the profile of training in the specialty 029 "Information, library and archives", and is based on the approaches of representatives of the scientific and pedagogical school of library and information education to the understanding of the essence of information management, and takes into account the current trends in the development of information management. Conclusions. The study demonstrates that to ensure the compliance of the content of the subject area (information and document systems of institutions, technologies for managing information, archives and library) and understanding of information management as the manage ment of information and management with the help of information taking into account the communicative component, it is necessary to develop a holistic concept in systematic research and provide a didactic translation of scientific results into the educational process in the training course "Information Management" for students of the specialty "Information, library and archives". Therefore, the development of a holistic theory of information management, the main provisions of which could become the basis for the content of the discipline, is necessary for the comprehensive training of specialists in this field.

Keywords: information management; training; specialty 029 "Information, library and archives"

\section{- ПРОБЛЕМНЫЕ КОНТЕКСТЫ СОВРЕМЕННОЙ ГУМАНИТАРИСТИКИ: КОНЦЕПТУАЛЬНЫЕ ОСНОВЫ СОДЕРЖАНИЯ УЧЕБНОЙ ДИСЦИПЛИНЫ «ИНФОРМАЦИОННЫЙ МЕНЕДЖМЕНТ»}

\section{- Касьян Владислав Владимирович}

Кандидат философрских наук,

ORCID: 0000-0003-0539-4531, e-mail: kasjanvv@gmail.com, Киевский национальный университет культуры и искусств, Киев, Украина

\section{- Аннотация}

Цель статьи - выявление концептуальных основ формирования содержания дисциплины «Информационный менеджмент» для подготовки специалистов по специальности 029 «Информационное, библиотечное и архивное дело». Методология исследования базируется на совокупности общенаучных методов обобщения, систематизации и прогнозирования. Гипотетический анализ позволил разработать содержание дисциплины «Информационный менеджмент» для специальности 
029 «Информационное, библиотечное и архивное дело» по предметной области деятельности будущего специалиста и стандарта высшего образования по специальности. Научная новизна исследования заключается в том, что обоснован концептуальный подход к содержанию учебной дисциплины «Информационный менеджмент», релевантный профилю подготовки специалистов по специальности 029 «Информационное, библиотечное и архивное дело», основанный на подходах представителей научнопедагогической школы библиотечно-информационного образования в понимании сущности информационного менеджмента и учитывающий современные тенденции развития наук информационно-управленческого направления. Выводы. Доказано, что для соответствия содержания предметной области (информационные и документные системы учреждений, технологии управления информационными, архивными и библиотечными делами), и понимания информационного менеджмента как управления информацией и управления с помощью информации с учетом коммуникативной составляющей деятельности, в учебном курсе «Информационный менеджмент» для студентов специальности «Информационное, библиотечное и архивное дело» необходимо выработать целостную концепцию в системных исследованиях и обеспечить дидактическую трансляцию научных результатов в учебный процесс. Поэтому разработка целостной теории информационного менеджмента, основные положения которой могли бы стать основой содержания данной учебной дисциплины, является необходимой для всесторонней подготовки специалистов указанной отрасли.

Ключевые слова: информационный менеджмент; подготовка специалистов; специальность 029 «Информационное, библиотечное и архивное дело» 